\title{
Effect of Website Quality Factors on the Success of Agricultural Products B2C E-commerce
}

\author{
Ping $\mathrm{Yu}^{1}$ and Dongmei Zhao ${ }^{2}$ \\ ${ }^{1}$ School of Economics \& Management, China Agricultural University, Beijing 100083, China \\ yuping@cau.edu.cn \\ ${ }^{2}$ China Agricultural University, Beijing 100083, China \\ zhaodongmevip.163.com
}

\begin{abstract}
By applying analytic hierarchy process to extend the D\&M IS success model, this paper builds a user preference hierarchical model for online consumers to select the most preferred website; this model is mainly constituted by the quality of information, service, system and supplier. Empirical study on agricultural products $\mathrm{B} 2 \mathrm{C}$ field has shown that service quality is the most important factor affecting the website selections of online consumers, and ecommerce businesses should make greater efforts to improve the reliability and the rapid responsiveness of service. As supplier quality is highly correlated with user preferences, e-commerce businesses should take a balance strategy to increase product range, improve product quality with lower product price at the same time Information currency is high in the ranking, so e-commerce businesses should pay attention to update information on the website timely.
\end{abstract}

Keywords: B2C, E-commerce success, website quality factors.

\section{Introduction}

With the popularity of internet and people's love for shopping, consumerism has already been popular in China. In 2006, less than $10 \%$ of users shop online, while in 2012 this proportion has jumped to 39\%. The intense growth of internet users promotes the rapid development of Chinese e-commerce market, data from China Electronic Commerce Research Center shows that as of June 2012, the Chinese ecommerce market transactions amounted to 3.5 trillion Yuan, increased by $18.6 \%$.The generous profits of e-commerce market has attracted more and more businesses to enter, at the same time, the surge of e-commerce businesses makes the competition of Chinese e-commerce market fierce. In 2012, some e-commerce businesses cut down part of staffs, some e-commerce businesses went bankrupt, China Electronic Commerce Research Center analyst, Mo Dai Qing believes that the failures of ecommerce businesses will continue, superior bad discard will continue to unfold. However, many decision-makers of e-commerce businesses are continuing to make significant investment in developing e-commerce websites, in case of not being clear what factors contribute to the development of high-quality websites and how to measure their effect on e-commerce success [1-2]. 
E-commerce is a special business industry, it is different from others, and the success of an e-commerce business depends largely on its website quality [38]. As a portal for business to interact with the current and potential consumers, website not only provides a platform for businesses to promote products and services, but also provides a way to generate more revenue by attracting more consumers. On the one hand, e-commerce businesses rely on people to visit their websites to buy their products, and more importantly, become repeated customers; On the other hand, consumers have a lot of alternative sites to choose from, so if a website's performance cannot let consumers be satisfied, they can easily switch to another alternative website. Therefore, the website quality of an e-commerce business will directly affect consumers to go or stay, and then determines e-commerce success.

Domestic and foreign researchers have made considerable efforts in determining the factors affecting e-commerce success. DeLone and McLean [3] first proposed IS success model in 1992, and subsequently based on it they proposed the updated D \& M IS success model [4], which can measure the success of e-commerce systems from six dimensions: information quality, system quality, service quality, use, user satisfaction and net benefits. Molla and Licke [5] partially extended and modified the D \& M IS success model, and then proposed an e-commerce success model. They regarded the consumer e-satisfaction as the dependent variable of e-commerce success, defined and discussed the relationship between the consumer e-satisfaction and e-commerce system quality, content quality, use, trust and support. Madeja and Schoder [6] conducted an empirical research on 8 website performance indicators which affect the success of e-commerce system: interactivity, immediacy, connectivity, diversity, availability, information-rich, usability, personalization and customizations. Xuan [7] studied the factors which impact the e-commerce success of network marketing companies, taking China Shanghai Brilliance Group as a case. Mainly referencing Molla \& Licker (2001) e-commerce success model, he selected four indicators: system quality, content quality, trust, support and service to measure the success of e-commerce systems. Sharkey et al. [8] empirical studies the updated D \& M IS success model, they found the important relationship between information quality, system quality, and three success dimensions: intention to use, user satisfaction and trading intent.

Although in order to determine the website quality factors affecting e-commerce success, researchers have conducted a number of studies and provided a deep understanding of it, but it still has exploration space being left, for example, we can add more website quality factors to extend the existing models, we can also apply the models to different e-commerce domains to compare and analyze.

This paper assumes that an e-commerce business is more likely to be success when its website has the highest quality among all the alternatives. This will result in its website being selected by online customers as the most preferred. The more customers select its website, the more likelihood the business improves its ecommerce business performance. This paper addresses this issue, limiting the study scope to an investigation of website quality of agricultural products $\mathrm{B} 2 \mathrm{C}$ e-commerce websites. 


\section{Theoretical Framework}

\subsection{Updated D\&M IS Success Model}

In order to measure the success of information systems, researchers have proposed many theoretical models. Among these models, DeLone and McLean's IS success model is the most cited models.

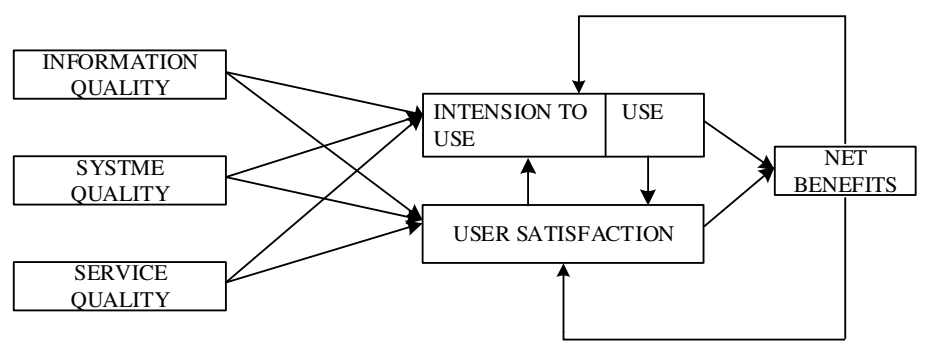

Fig. 1. Updated DeLone \& McLean IS Success Model

In 2003, DeLone and McLean updated there IS success model based on other researchers' findings, as shown in Fig.1. Delone and McLean added "service quality" to the model, and merged the two dimensions: "individual impact" and "organizational impact" into a single new indicators: net benefits. DeLone and McLean believe that the IT department of an organization not only provides product information to consumers, but also provides service support to consumers, so service quality should also be one of the dimensions of information systems success; In addition, according to the different levels of analysis and research purposes, except for "individual impact", there also may have "industry impact," "social impact", "consumer impact" and so on, and "impact" may be positive or negative, so "individual impact " and "organizational impact" in the original model are not comprehensive enough and the more comprehensive and accurate concept " net benefit" should be used as the ultimate success dimension, and the situation of " net benefit "will adversely affect system use and user satisfaction.

Because e-commerce system is one kind of information system, so D\&M IS success model can also be used to measure the effectiveness and the value of ecommerce system.

\subsection{Analytic Hierarchy Process [9-10]}

AHP is proposed by an American operational research experts Saaty in the 1970s, it is a multi-objective decision analysis method which combines qualitative and quantitative analysis. 
The principle of this method is as follows:

Assuming there are $n$ objects, denoted as $A_{1}, A_{2}, \ldots, A_{n}$, their weights are $w_{1}, w_{2}, \ldots, w_{n}$. If they compare their weights two by two, the ratio may constitute a $\mathrm{n} \times \mathrm{n}$ matrix $A$.

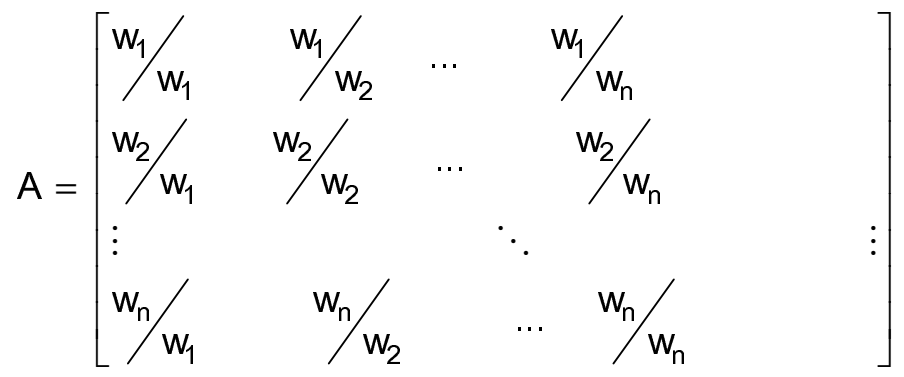

Matrix A has the following properties:

If using the weight vector $W=\left(w_{1}, w_{2}, \cdots, w_{n}\right)^{\top}$ to right multiply matrices $A$, the results is as follows:

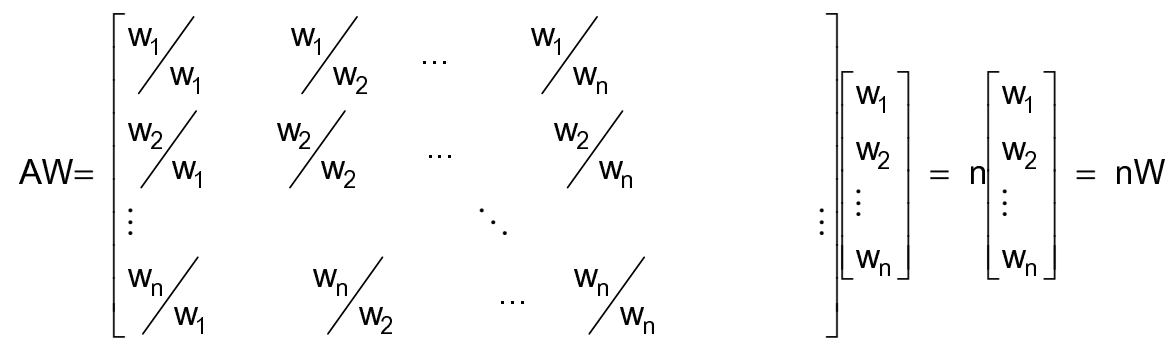

$\operatorname{Namely}(A-n l) W=0$.

Seen by the matrix theory, his the feature vector, $\mathrm{n}$ is the characteristic value. If $\mathrm{W}$ is unknown, we can make a judgment of radio subjectively based on the relationship comparing between objects by policymakers or use the Delphi method to obtain these ratios to make the matrix $A$ to be known, and then the judgment matrix is recorded as $\overline{\mathrm{A}}$.

According to the theory of positive matrix, we can prove: If the matrix $A$ has the following characteristics $\left(\left(a_{i j}=w_{i} / w_{i}\right)\right.$ :

1) $a_{i j}=1$

2) $a_{i j}=1 / a_{j i}(i, j=1,2, \ldots, \quad n)$

3) $a_{i j}=a_{i k} / a_{j k}(i, j=1,2, \ldots$

Then the matrix has a unique maximum eigenvalue nonzero $\lambda_{\max }$ and $\lambda_{\max }=\mathrm{n}$. 
If the given judgment matrix $\bar{A}$ having the above characteristics, then this matrix has full consistency. However, when people pairwise compares the various factors on complex things, it is impossible to achieve complete consistency of judgment, but there is estimation error, which will inevitably lead eigenvalues and eigenvectors also have bias. Then the question changes to $\bar{A} \dot{W}=\lambda_{\max } \dot{W}$ from $A W=n W$, here $\lambda_{\text {max }}$ is the largest eigenvalue of matrix $\bar{A}, W$ and is the relative weight vector with deviations. This is the errors caused by incompatible judgment. To avoid the error is too large, so it need to measure the consistency of the matrix $\bar{A}$. When matrix $A$ is fully consistent:

Because $a_{i i}=1, \sum_{i=1}^{n} \lambda_{i}=\sum_{i=1}^{n} a_{i j}=n$,

So there exists a unique nonzero $\lambda=\lambda_{\max }=\mathrm{n}$. And when the discrimination of Matrix $\bar{A}$ exists inconsistent, in generally $\lambda_{\max } \geq n$.

$$
\text { Here }_{\lambda_{\text {max }}}+\sum_{i \neq \max } \lambda_{i}=\sum_{i=1}^{b} a_{i i}=n \text {. }
$$

Due to $\lambda_{\max }-\mathrm{n}=-\sum_{\mathrm{i} \neq \max } \lambda_{i}$.

Use its mean as the index of inspection judgment matrix.

When $\lambda_{\max }=\mathrm{n}, \mathrm{C} . \mathrm{I}=0$, it is fully consistent; the larger the value of $\mathrm{C.I}$ is, the worse the complete consistency of judgment matrix is. Usually as long as C.I $\leq 0.1$, it is considered the consistency of judgment matrix is acceptable, otherwise, it needs to re-pairwise the comparison judgments. The greater the dimensions of Matrix $n$ is, the worse the consistent of judgments is. Thus the correction value R.I is introduced. As shown in table 1. And taking a more reasonable value of $C . R$ as the indicators to measure the consistency of judgment matrix.

$$
\text { C. } R=\frac{\text { C.I }}{\text { R.I }}
$$

Table 1. Correction value R.I

\begin{tabular}{l|l|l|l|l|r|r|r|r|r}
\hline Dimension & 1 & 2 & 3 & 4 & 5 & 6 & 7 & 8 & 9 \\
\hline R.I & 0.00 & 0.00 & 0.58 & 0.96 & 1.12 & 1.24 & 1.32 & 1.41 & 1.45 \\
\hline
\end{tabular}

\section{Research Model}

Base on D \& M updated IS success model (2004) and AHP, this paper proposes a research model (Fig.2) for online consumers to select the most preferred website. The model consists of four main website quality factors including information quality, system quality, service quality, and supplier quality. We believe that these four website quality factors significantly affect the online consumers to choose the most preferred website. 


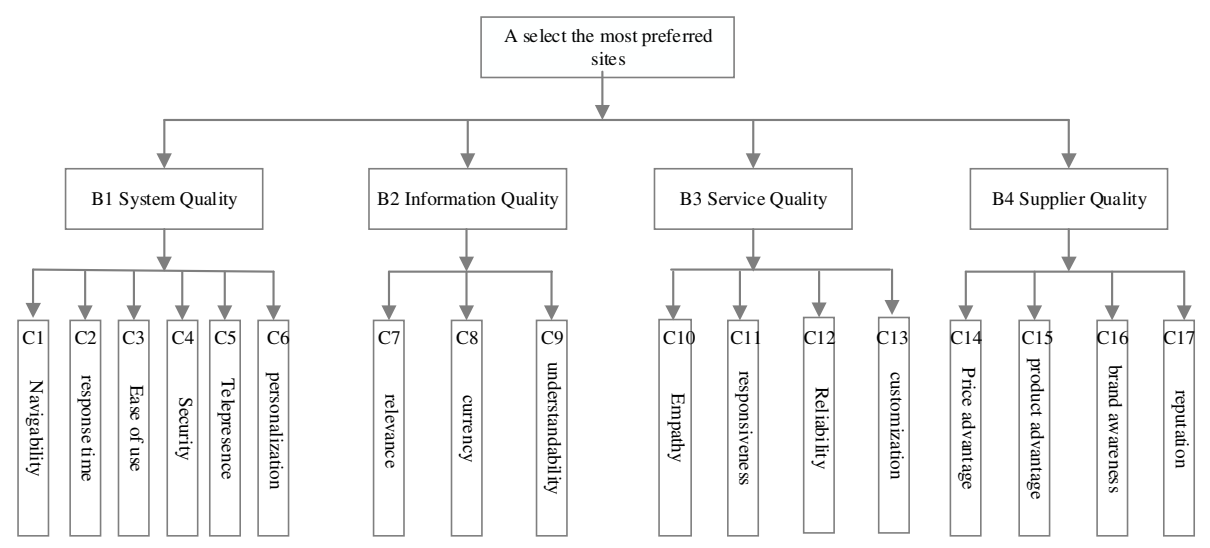

Fig. 2. User Preference Hierarchy Mode

\subsection{Information Quality}

Because of the characteristics of virtual environment, online consumers can not physically touch the products, therefore, product information on the website is the only way by which online consumers can understand products. In some studies information quality is also known as content quality. Some researchers define information quality as the characteristics and expression of information in the ecommerce system [11-12]. Alba and other studies suggest that information quality refers to to what extent online consumers can use information to predict their subsequent consumer satisfaction prior to purchase [15]. Previous studies have demonstrated that information quality and its sub-properties can improve customer satisfaction and maintain a website's attraction to consumers [13-14].

Information quality can be measured by information relevance, currency and understandability. Information relevance includes the relative depth, range and integrity of information. Currency refers that information should be updated timely, studies have found that frequent updates can improve the access rate [15], while outdated information is a primary factor that causes website closure and business failures [16]. Understandability means information content should be clear and easy to be understood.

\subsection{System Quality}

System quality used to measure the characteristics e-commerce system requires [17]. System quality is believed to be a critical success factor affects technology use and user satisfaction. Research shows that websites with poor system quality will let consumers to have a negative impact on online experience and consumer satisfaction [18-19]. System quality can be measured by navigability, response time, ease of use, security, telepresence and personalization. 
Navigability refers to the interactivity and navigation technology capabilities a website provides [20]. Navigability can not only provide more control navigation for online consumers, but also can help online consumers to reach the target website with fewer obstacles [21]. Fast response time is very important for improving system quality because few online consumers are willing to wait more than a few seconds to be respond. Ease of use is an important factor for e-commerce system [22], which is treated as one dimension of success in the D \& M IS success model. Telepresence is defined as the realism in a virtual environment created by the computer / communications media. We know that online consumers want to feel and touch the products and communicate with retailers as they do in the physical market, they tend to use their experiences in the real world as a standard to evaluate their online experiences [23-24]. In order to locate and select the best products and service on websites, online consumers often need to experience an excessive amount of information, so it does need a personalized system to treat every consumer separately [25-26], a personalized system can provide online consumers with personalized interfaces, effective one to one information and personalized service [27-28].Finally, security is one of the biggest obstacles for e-commerce. Online consumers will not disclose their personal information and financial information until they are sure a website is secure, so the website should achieve a variety of functions (for example: encryption, third-party certification, Security Statement) to ensure the security of online shopping [29].

\subsection{Service Quality}

Service Quality is the comprehensive support offered by the online retailer. Because online consumers are trading with invisible retailers, so service quality has become particularly important in e-commerce [20]. Service quality can be measured by empathy, responsiveness, reliability and customization.

Empathy refers to the care and attention provided by e-commerce businesses to online consumers [30].Responsiveness is the willingness e-commerce businesses provide timely services to help online shoppers [30]. Reliability is the capabilities ecommerce businesses fulfill service warranty reliably and accurately [30]. Customization is another important service activity on the website [31], it is the customized information, products and prices provided by e-commerce businesses to online consumers based on the track of the interaction between online consumers and their websites. [32]; through customization e-commerce businesses can further differentiate their competitors, and encourage online consumers to return to their websites for the next shopping event [33].

\subsection{Supplier Quality}

Supplier quality is also considered an important factor of e-commerce success. Supplier quality can be measured by price advantage, product advantage, brand awareness and reputation. 
Price advantage is a measure of store efficiency, because a valid store can reduce transaction costs and thus provide consumers with better prices [34]. It is discovered that price advantage has important implications for online purchase, for example, Devaraj et al found that price advantage significantly affects e-commerce channel satisfaction of books or CDs [35]; Chen and Dubinsky's studies have shown that high price has a negative impact on online consumers [36]. Product categories is one of the most important factors that affect e-commerce success [37], providing a range of products can improve the efficiency of e-commerce transactions, because online consumers will not have to search products on other websites and thus saving time for online consumers, as well as increasing trading revenues for e-commerce businesses; while quality problems will affect consumers' confidence in e-commerce suppliers [38]. Websites with good brand positioning will attract high click-through rate [39], a customer's brand loyalty is positively correlated with his website loyalty [40], and users are more willing to choose the technology choose by a large number of other users [41]. E-commerce business spends millions of dollars to advertise its website to improve its brand awareness, when a lot of people know and want to experience a website, the website's brand awareness has been improved. Economists found reputation is positively correlated with prices, the higher an e-commerce business's reputation is, and the more consumers are willing to pay for the e-commerce business.

\section{$4 \quad$ Research Method}

\subsection{Data Collection}

A questionnaire-based online survey was conducted to investigate the relative importance of website quality factors for online customers to select the most preferred website. The factor and their measurement items were initially developed based on a literature review. Then, we invited three business doctoral tutor and six doctoral students to check the wording, content, and format of the questionnaire, and according to their views the questionnaire was modified.

The questionnaire is divided into three parts. The first part investigates the demographic characteristics of the survey respondents, including: gender, age, educational background and career; the second part investigates the network familiarity and shopping habits of the survey respondents, including: contact time of online shopping, number of online shopping average weekly; The third part investigate the relative importance of website quality factors for the survey respondents by pairwise comparing.

First, each survey respondent was required to navigate an agricultural product B2C websites to conduct tasks based on a given online purchasing scenario. Then each survey respondent was asked to fill out the questions about the relative weight of one factor over another. Finally, each survey respondent was demand to visit all the target websites and answer the questions about relative strength of each alternative website based on each factor. 
We adopted online survey questionnaire to collect data. The web-based survey began from February 15 and ended at March 15 in 2012. Finally we received 338 questionnaires and 310 were valid.

\subsection{Descriptive Analysis}

In the effective research samples, male and female ratio is about $1: 1$, men slightly more than women. Samples under 35 years account for 82.91 percent, which have an absolute advantage. Undergraduate and equivalent account for $59.03 \%$ in the total sample. AS to thire average monthly expenditure for online shopping in the last three months, 3000-5000 Yuan accounts for 20.65\%, which ranked first. And among their average monthly expenditure for online shopping, 500-1000 Yuan shares the largest proportion, accounts for $43.87 \%$. Company or enterprise managers share the highest percentage $33.35 \%$, followed by the general staff, accounting for $28.39 \%$, and then followed by professional and technical personnel, accounting for 18.71 percent. Analysis of the basic demographic characteristics of samples illustrates they have the very similar online shopping user characteristics published by CNNIC.

In addition, we can also see that $37.74 \%$ of samples have more than 4 years online shopping experiences; $79.35 \%$ of samples shopped online more than twice an week in the recent three months. More than $75 \%$ of samples spent more than to 2 hours a week to browse online shopping information. Analysis of shopping habits of samples illustrates they have more frequent and stable shopping habits.

\section{$5 \quad$ Results and Discussion}

The data was analyzed by Expert Choice. Expert Choice is an AHP software, which can provide analysis results including local weights, overall weight, the priority of alternatives and sensitivity.

\subsection{Comparison of Website Quality Factors}

First, we analyze the relative importance of website quality factors, check the importance of each factor contributing for consumers to choose the most preferred online website. In order to obtain the relative importance of each factor, we conducted a pairwise comparison of factors. The weight of each website quality factor is shown in Fig.3. 


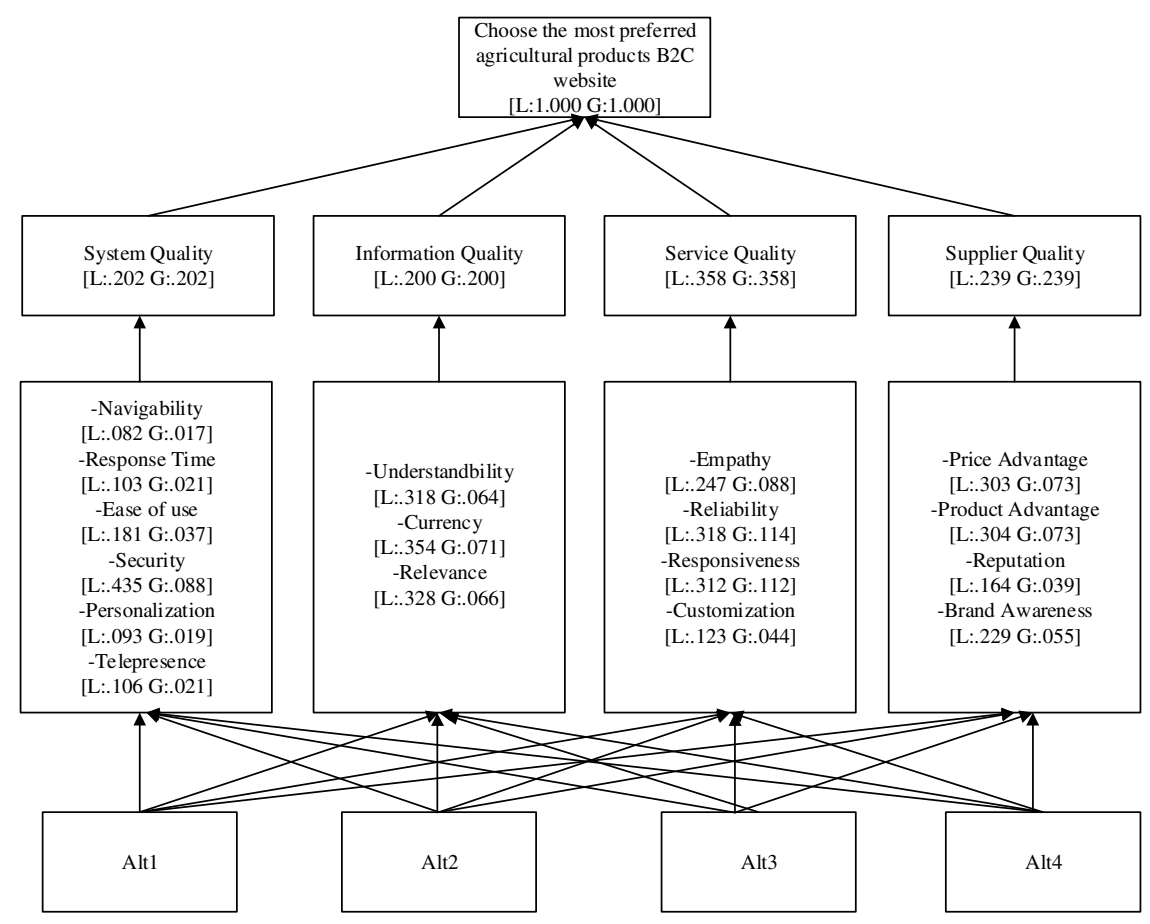

Fig. 3. Relative importance of website quality factors

From Fig.3, we can see that when online consumers choose agricultural products ecommerce websites, service quality has the highest global weight 0.358 , followed by supplier quality (0.239) and system quality (0.202). This fully verifies that service quality is increasingly becoming an important aspect of e-commerce [42]. For system quality, safety has the highest local weights 0.435 , followed by ease of use $(0.181)$, telepresence (0.106), personalization (0.093), and navigability (0.082). For information quality, currency has the highest local weights 0.354 , followed by relevance $(0.328)$, understandability $(0.318)$. For service quality, reliability has the highest local weights 0.318 , followed by responsiveness $(0.312)$, empathy $(0.247)$ and customization (0.123). For supplier quality, price advantage tied with product advantages have the highest local weights 0.73 , followed by brand awareness $(0.229)$ and reputation $(0.164)$.

The ranking of website quality factors is shown in Table 2.

From Table 2 we can see that when online consumers choose the most preferred website, the reliability, responsiveness, empathy of service quality, the security of system quality, the price advantage and product advantages of supplier quality, and the currency of information quality are among the top five website quality factors. 
Table 2. Ranking of website quality factors

\begin{tabular}{lll}
\hline & Global weights & Rank \\
\hline Navigability & 0.017 & 14 \\
Response Time & 0.021 & 12 \\
Ease of use & 0.037 & 11 \\
Telepresence & 0.021 & 12 \\
Security & 0.088 & 3 \\
Personalization & 0.019 & 13 \\
Understandability & 0.064 & 7 \\
Currency & 0.071 & 5 \\
Relevance & 0.066 & 6 \\
Reliability & 0.114 & 1 \\
Responsiveness & 0.112 & 2 \\
Empathy & 0.088 & 3 \\
Customization & 0.044 & 9 \\
Brand Awareness & 0.039 & 10 \\
Reputation & 0.055 & 8 \\
Price Advantage & 0.073 & 4 \\
Product Advantage & 0.073 & 4 \\
\hline
\end{tabular}

\subsection{Comparisons of Alternative Websites}

Alternative websites are websites which can substitute for each other to meet a certain kind of consumers' desire. As more and more e-commerce websites being created, the homogenization of e-commerce websites becomes increasingly serious, how to create a differentiated competitive advantage, is the problem which e-commerce businesses have to face if they want to successfully survive.

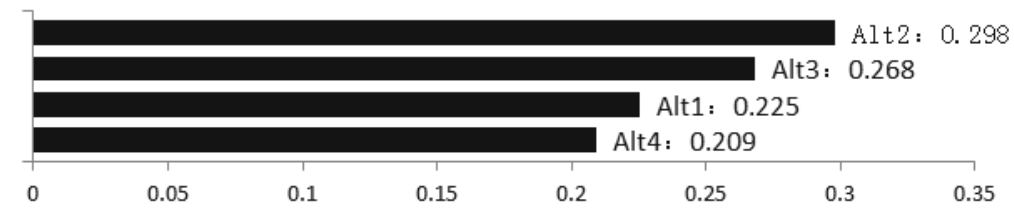

Fig. 4. Ranking of Alternative websites

Fig. 4 shows the result of the most preferred website choose by online consumers. We can see Alt2 (0.298) are the most preferred site of online consumers, followed by Alt3 (0.268), Alt1 (0.225), and Alt4 (0.209). 
Table 3. Ranking of website quality factors

\begin{tabular}{lllll}
\hline & Alt1 & Alt2 & Alt3 & Alt4 \\
\hline Navigability & 0.218 & 0.295 & 0.256 & 0.181 \\
Response Time & 0.337 & 0.245 & 0.263 & 0.115 \\
Ease of use & 0.283 & 0.304 & 0.243 & 0.170 \\
Telepresence & 0.267 & 0.264 & 0.252 & 0.237 \\
Security & 0.279 & 0.309 & 0.225 & 0.187 \\
Personalization & 0.278 & 0.283 & 0.268 & 0.172 \\
Understandability & 0.262 & 0.236 & 0.273 & 0.229 \\
Currency & 0.239 & 0.328 & 0.226 & 0.208 \\
Relevance & 0.156 & 0.335 & 0.307 & 0.203 \\
Reliability & 0.194 & 0.308 & 0.250 & 0.248 \\
Responsiveness & 0.212 & 0.234 & 0.343 & 0.211 \\
Empathy & 0.224 & 0.355 & 0.233 & 0.189 \\
Customization & 0.180 & 0.308 & 0.268 & 0.244 \\
Brand Awareness & 0.231 & 0.323 & 0.263 & 0.183 \\
Reputation & 0.172 & 0.295 & 0.302 & 0.231 \\
Price Advantage & 0.271 & 0.305 & 0.211 & 0.212 \\
Product Advantage & 0.182 & 0.302 & 0.320 & 0.196 \\
\hline
\end{tabular}

Table 3 shows the normalized priority weights of website quality factors. Through this table we can see that Alt2 which is the most preferred alternative website of online consumers has the highest navigability, ease of use, security, personalization, currency, relevance, reliability, customization, brand awareness and price advantage. Alt3 which ranks second has the highest service responsiveness, information understandability, and reputation and product advantages. Alt1 ranks third has the highest system response time and telepresence, while alt4 ranks last does not have outstanding website quality factors. Through this table, an e-commerce business can identify the gap of website quality factors between its website and their competitors', and thus develops the relevant strategies to improve the quality level of its website.

\subsection{Sensitivity Analysis}

Sensitivity analysis is to investigate when the weight of a factor or an indicator changes, how other factors or indicators change relatively. Expert Choice software provides three kinds of sensitivity analysis [43]: Dynamic Sensitivity Analysis, Performance Sensitivity Analysis, and Gradient Sensitivity Analysis.

Through sensitivity analysis, we can provide more information about how online retailers improve their website quality to catch up with competitors or how to maintain its position as the most preferred website.

The Gradient Sensitivity Analysis chart of System quality is shown in Figure 5. From Fig.5, we can see when the weight of system quality is greater than 0.646 , it may lead to Alt3 whose user preference ranking is second interchanges its ranking with Alt1 whose user preference ranking is third. This shows that if Alt1 greatly 
improves its system quality, it can improve its ranking among online consumers. When the weight of system's response time is greater than 0.08 , online consumers may replace the ranking of Alt2 and Alt3. This shows that if Alt 3 speed up its response time, then its user preference ranking may exceed Alt2.

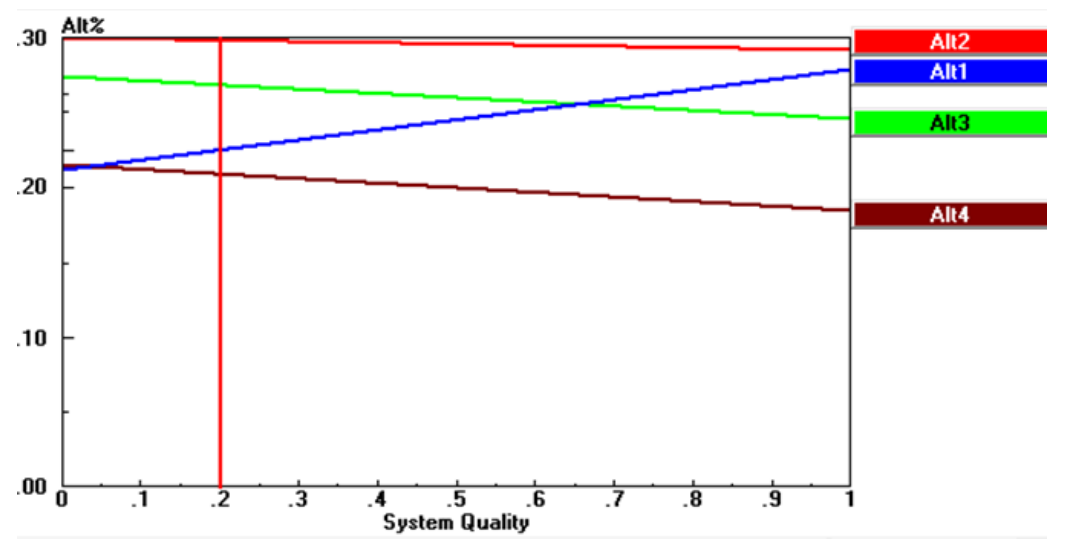

Fig. 5. Gradient Sensitivity Analysis chart of System quality

The Gradient Sensitivity Analysis chart of Service quality is shown in Fig.6, which indicates that when the weight of service quality is greater than 0.657 , online consumers may replace the ranking of Alt4 and Alt1. Therefore, if Alt4 wants to improve its user preference ranking, it needs to improve its service quality.

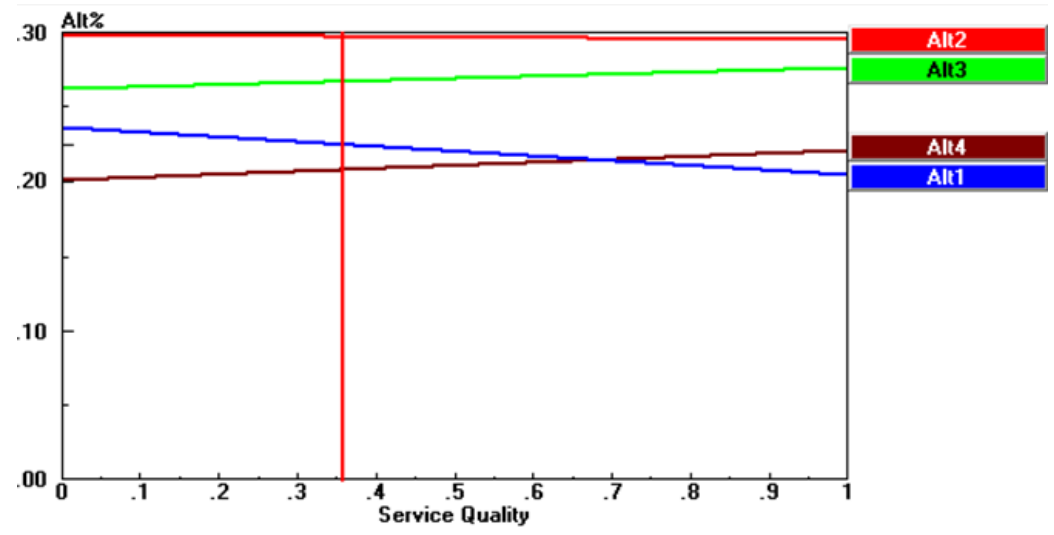

Fig. 6. Gradient Sensitivity Analysis chart of Service quality 


\section{Conclusions}

Through modifying updated D \& M IS success model and applying AHP, this paper explores the relative importance of website quality factors which affect online consumers to choose the most preferred websites and the priority of alternative websites. We found that when online consumers choose the most preferred website, service quality is considered to be the most important factor, among which reliability and responsiveness rank the highest, this suggests that e-commerce businesses should pay more effort to improve service reliability and rapid response. Supplier quality is highly relevant, product advantage and price advantage causes online consumers' concerns which shows e-commerce businesses should take the balancing strategy to increase product variety, improve product quality and at the same time lower product price. The currency of information quality is also top-ranking, indicating that ecommerce businesses should pay attention to update the information including product information and contact information on their website timely.

This paper has limitations, which needs to revisit in future studies. First, the results of this paper confines to the field of agricultural products $\mathrm{B} 2 \mathrm{C}$ e-commerce, not represents all e-commerce. Secondly, the evaluation factor is based on the updated D \& M IS success model, which may rule out some factors strongly affect the website quality. Third, because the target website is e-commerce website, which makes the validity study of each factor not in the controllable environment. Fourth, the sample used in this paper are not enough, it may lead to sample selection bias problem. Fifth, this paper is based on online survey, the sample's behavior is uncontrollable, which may result in deviation of sample data.

This paper empirically validates that the updated D\&M IS success model can successfully reveal e-commerce success; by adding ease of use factor in system quality, adding customization factor in service quality, adding product advantages factor in supplier quality, the initial model is extended. The results showed a significant effect. The extended model can be used to guide managers / designers to measure the level of their websites quality. With comparing with competitor's website quality, E-commerce businesses can develop strategies and resource allocation decisions to improve the current websites to obtain e-commerce success; Research models, standards and their relative impact not only provide useful information for decision-makers of e-commerce businesses to develop decision support systems to monitor the performance of the current websites, but also provides strategic advice for businesses to develop better e-commerce websites.

Acknowledgment. Funds for this research was provided by the National Natural Science Foundation of China (No.71271207).

\section{References}

1. Irani, Z.: Information systems evaluation: navigating through the problem domain. Information \& Management 40(1), 11-24 (2002)

2. Thornton, J., Marche, S.: Sorting through the dot bomb rubble: how did the high-profile e-tailers fail? International Journal of Information Management 23(2), 121-138 (2003) 
3. DeLone, W.H., McLean, E.R.: Information systems success: the quest for the dependent variable. Information Systems Research 3(1), 60-95 (1992)

4. Delone, W.H.: The DeLone and McLean model of information systems success: a ten-year update. Journal of Management Information Systems 19(4), 9-30 (2003)

5. Molla, A., Licker, P.S.: E-commerce systems success: An attempt to extend and respecify the DeLone and McLean model of IS success. Journal of Electronic Commerce Research 2(4), 131-141 (2001)

6. Madeja, N., Schoder, D.: Designed for success-empirical evidence on features of corporate web pages. In: Proceedings of the 36th Annual Hawaii International Conference on System Sciences, 2003, p. 10. IEEE (2003)

7. Xuan, W.: Factors affecting the achievement of success in e-tailing in China's retail industry: a case study of the Shanghai Brilliance Group. College of Management, Southern Cross University, Australia (2007)

8. Sharkey, U., Scott, M., Acton, T.: The influence of quality on e-commerce success: an empirical application of the Delone and Mclean IS success model. International Journal of E-Business Research (IJEBR) 6(1), 68-84 (2010)

9. Bo, Z.: AHP Fundamentals Introduction. Journal of Northwestern University (Natural Science Edition) 28(2), 109-113 (1998)

10. Wang, Y.: Systems Engineering, 2nd edn. Mechanical Industry Press (1999)

11. Von Dran, G.M., Zhang, P., Small, R.: Quality websites: An application of the Kano model to website design. In: Proceedings of the Fifth Americas Conference on Information Systems, pp. 898-900 (1999)

12. Zhang, X., Keeling, K.B., Pavur, R.J.: Information quality of commericial web site home pages: an explorative analysis. In: Proceedings of the Twenty First International Conference on Information Systems, pp. 164-175. Association for Information Systems (2000)

13. Alba, J., Lynch, J., Weitz, B., et al.: Interactive home shopping: consumer, retailer, and manufacturer incentives to participate in electronic marketplaces. The Journal of Marketing, 38-53 (1997)

14. Calkins, J., Farello, M., Shi, C.: From retailing to e-tailing. Strategic Direction 16(6), 17 (2000)

15. Dholakia, U.M., Rego, L.L.: What makes commercial Web pages popular? An empirical investigation of Web page effectiveness. European Journal of Marketing 32(7/8), 724-736 (1998)

16. Cogitative Building maintaining \& repairing web brand loyalty (EB/OL) (1999), http://www.cognitiative.com

17. Delone, W.H., Mclean, E.R.: Measuring e-commerce success: applying the DeLone \& McLean information systems success model. International Journal of Electronic Commerce 9(1), 31-47 (2004)

18. Chiger, S.: List shopping online. Catalog Age 14(7), 95-97 (1997)

19. Nielsen, J.: Seven deadly sins for web design. Technology Review 73(1), 9A-10A (1998)

20. Marsico, M.D., Levialdi, S.: Evaluating web sites: exploiting user's expectations. International Journal of Human-Computer Studies 60(3), 381-416 (2004)

21. Carver, D.L.: Designing the user interface, strategies for effective human-computer interaction. Journal of the American Society for Information Science 39(1), 22-22 (1988)

22. Horsti, A., Tuunainen, V.K., Tolonen, J.: Evaluation of electronic business model success: Survey among leading Finnish companies. In: Proceedings of the 38th Annual Hawaii International Conference on System Sciences, HICSS 2005, p. 189c. IEEE (2005) 
23. Steuer, J.: Defining virtual reality: Dimensions determining telepresence. Journal of Communication 42(4), 73-93 (1992)

24. Klein, L.R.: Creating virtual product experiences: the role of telepresence. Journal of Interactive Marketing 17(1), 41-55 (2003)

25. Lombard, M., Snyder-Duch, J.: Interactive advertising and presence: a framework. Journal of Interactive Advertising 1(2), 56-65 (2001)

26. Riecken, D.: Personalized views of personalization. Communications of the ACM 43(8), 27-28 (2000)

27. Zhang, Y., Im, I.: Recommendation systems: a framework and research issues. In: The Proceedings of Americas Conference on Information Systems, pp. 468-473 (2002)

28. Murthi, B.P.S., Sarkar, S.: The role of the management sciences in research on personalization. Management Science 49(10), 1344-1362 (2003)

29. Schonberg, E., Cofino, T., Hoch, R., et al.: Measuring success. Communications of the ACM 43(8), 53-57 (2000)

30. Singh, M.: A primer on Developing an E-business Strategy. Western Illinois University (2002)

31. Morelli, W., Clark, G., Tesler, S.: Up close and personal. Best's Review 101(9), 99-100 (2001)

32. Roman, E.: Ready, fire, aim (EB/OL) (2005), http : / /www. Direct. com

33. Epstein, M.J.: Implementing successful e-commerce Initiatives. Strategic Finance 86(9), $22(2005)$

34. Bakos, J.Y.: Reducing buyer search costs: implications for electronic marketplaces. Management Science 43, 1676 (1997)

35. Devaraj, S., Fan, M., Kohli, R.: Antecedents of B2C channel satisfaction and preference: validating e-commerce metrics. Information Systems Research 13, 316-333 (2002)

36. Chen, Z., Dubinsky, A.J.: A conceptual model of perceived customer value in ecommerce: a preliminary investigation. Psychology and Marketing 20, 323-347 (2003)

37. Smith, P.: Hi tail to E-tail. New Zealand Management 47(6), 22 (2000)

38. Ba, S., Pavlou, P.A.: Evidence of the effect of Trust building technology in electronic markets: price premiums and buyer behavior. MIS Quarterly 26(3), 243-268 (2002)

39. Epstein, M.J.: Implementing successful e-commerce Initiatives. Strategic Finance 86(9), $22(2005)$

40. Teerling, M.L., Huizingh, E.K.R.E.: How about integration: the impact of online activities on store satisfaction and loyalty. University of Groningen (2003)

41. Markus, M.L.: Electronic mail as the medium of managerial choice. Organization Science 5, 502-527 (1994)

42. Santos, J.: E-service quality: a model of virtual service quality dimensions. Managing Service Quality 13(3), 233-246 (2003)

43. T.C. \& Forman. Pennsylvania: Expert Choice, Pittsburgh (1996) 